\title{
Interaction of a nascent RNA structure with RNA polymerase is required for hairpin-dependent transcriptional pausing but not for transcript release
}

\author{
Irina Artsimovitch and Robert Landick ${ }^{\mathbf{1}}$ \\ Department of Bacteriology, University of Wisconsin, Madison, Wisconsin, 53706 USA
}

\begin{abstract}
Nascent RNA structures may regulate RNA chain elongation either directly through interaction with RNA polymerase or indirectly by disrupting nascent RNA contacts with polymerase or DNA. To distinguish these mechanisms we tested whether the effects of the his leader pause RNA hairpin could be mimicked by paining of antisense DNA or RNA oligonucleotides to the nascent transcript. The his pause hai rpin inhibits nucleotide addition when it forms 11 nucleotides from the transcript 3' end. It also can terminate transcription when base changes extend its stem to $\leqslant 8$ nucleotides from the $3^{\prime}$ end. All oligonucleotides that disrupted the pause hairpin reduced the dwell time of RNA polymerase at the pause site dramatically, even when they mimicked the 11-nucleotide 3'-proximal RNA spacing or created a suitably positioned RNA loop. Oligonucleotides that paired $\leqslant 8$ nucleotides from the pause RNA $3^{\prime}$ end could trigger transcript release, but only when added to an al ready paused complex. These results argue that direct interaction of a nascent RNA hairpin with RNA polymerase delays escape from a pause, but that indirect effects of a hai ipin may trigger transcript release from a paused complex. Resistance of the paused complex to pyrophosphorolysis and its reversal by antisense oligonucleotides further suggest that interaction of the pause hairpin with RNA polymerase disengages the RNA $3^{\prime}$ end from the active site.
\end{abstract}

[Key Words: RNA polymerase; RN A hairpins; pausing; termination]

Received June 2, 1998; revised version accepted August 7, 1998.

$\mathrm{N}$ ascent RN A hairpins are components of certain classes of intrinsic pause and termination signals that regulate RNA chain elongation (traditionally called $\rho$-independent terminators and hairpin-dependent pause sites; for review, see Richardson and Greenblatt 1996; Uptain et al. 1997). Either pausing or termination can be stimulated by these RNA structures, depending on their distance from the pause or terminated RNA $3^{\prime}$ end and the surrounding RNA and DNA sequences (Chan et al. 1997). A central question about the effects of nascent RNA hairpins is whether they influence transcription through direct interactions with RNA polymerase (RNAP) or if their principal effects on the transcription complex (TC) are indirect and reflect removal of the nascent RNA chain from other interactions.

At the well-characterized his leader pause site, a nascent RNA hairpin is one of four components of a multipartite pause signal that directs pausing in a two-step mechanism (Fig. 1). The pause signal consists of the 5-bp stem, 8-nucleotide loop pause hairpin, the 11-nucl eotide 3 '-proximal region between the pause hairpin and the

${ }^{1}$ Corresponding author.

E-MAIL landick@macc.wisc.edu; FAX (608) 262-9865. pause RNA $3^{\prime}$ end, the two bases in the active site, and the DN A duplex downstream from the active site (Chan and Landick 1993). In the first step of the mechanism, isomerization to a paused conformation competes with bypass of the pause site. In the second step, the paused RN AP escapes slowly back to a rapidly el ongating conformation by nucleotide addition. The isomerization versus bypass competition is controlled principally by the 3'-proximal and downstream DN A sequences, which probably slow bypass by causing transient backtracking of the TC (Wang et al. 1995; Landick 1997; see Discussion). All four components inhibit pause escape from a single kinetic intermediate, probably by interfering with proper alignment of the $3^{\prime} \mathrm{OH}$ group and the incoming GTP (Chan et al. 1997; illustrated in Fig. 1 by separation of the $3^{\prime} \mathrm{OH}$ and NTP-binding subsites; see Discussion).

On the basis of RNA cross-linking experiments, the pause hairpin appears to contact the 904-950 region of the $\beta$ subunit in the paused TC and to disrupt nascent RN A contact to the amino-terminal region of $\beta^{\prime}$ (Wang and Landick 1997). The effects of the pause hairpin can be eliminated at $\geqslant 0.5 \mathrm{M} \mathrm{Cl}^{-}$ion, which, together with other salt effects, suggests that the pause hairpin slows nucleotide addition through a direct, $\mathrm{Cl}^{-}$-sensitive inter- 


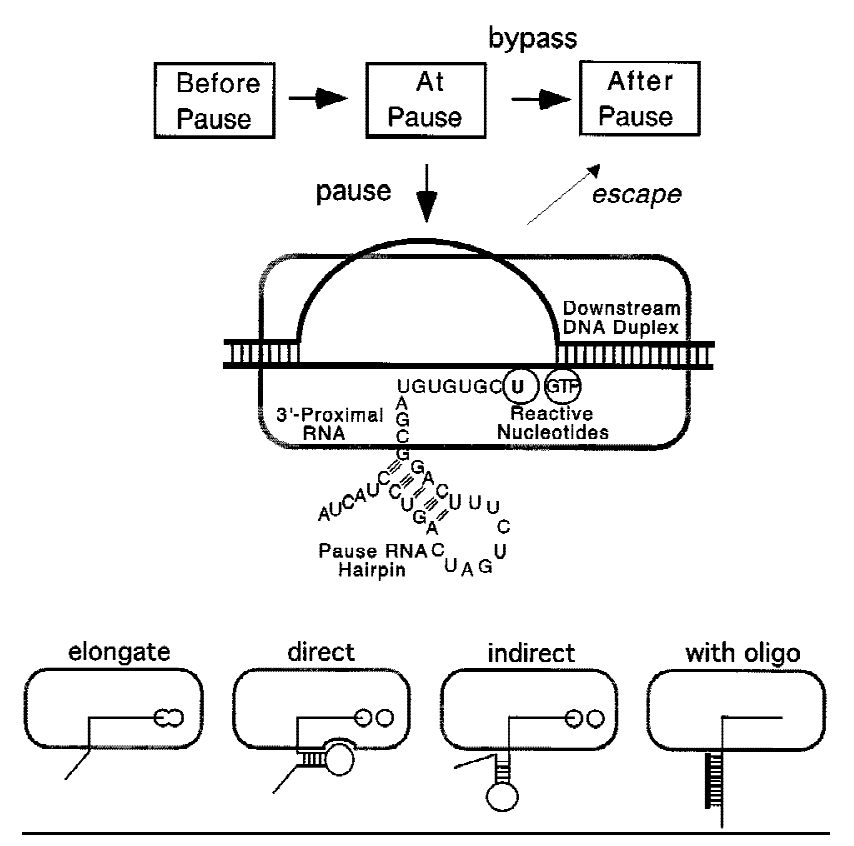

Figure 1. Possible effects of antisense oligonucleotides on hairpin-dependent pausing. (Top) The mechanism of hairpindependent transcriptional pausing. The four components of the his pause signal are labeled on the paused TC, which is formed in competition with bypass of the site and then slowly escapes back into the elongation pathway. How the pause hairpin inhibits nucleotide addition is unknown, but it presumably disrupts reactive alignment of the RNA $3^{\prime} \mathrm{OH}$ and incoming NTP (depicted here by separation of the $3^{\prime} \mathrm{OH}$ and NTP-binding subsites, $i$ and $i+1$; see Fig. 7). (Bottom) In the direct model of hairpin-dependent pausing, a specific interaction between the RN A hairpin and its binding site on RN AP disrupts nucleotide addition in the active site of RN AP (Chan et al. 1997; Wang and Landick 1997). In the indirect model, the hai rpin merely defines a particular length of 3'-proximal, single-stranded RNA transcript and thus could both disrupt RNA-RNAP interactions re quired for elongation or TC stability and prevent backtracking of RNAP along the DNA template (Komissarova and Kashlev 1997b; N udler et al. 1997). A nnealing of antisense oligonucleotides to the nascent RN A would be able to recapitulate indirect effects of hairpins, but not direct effects.

action with an easily disordered region of RN AP (Chan et al. 1997). However, it remains possible that the pause hairpin affects pausing indirectly by interfering with the $\beta^{\prime}$ interaction or by defining a particular length of $3^{\prime}$ proximal RNA.

$\rho$-Independent terminators also are multipartite signals, in which a G/C-rich nascent RNA hairpin is located 7-9 nucleotides from the point of release (d'Aubenton Carafa et al. 1990). The intervening 3'proximal RNA is shorter than at the his pause site, is typically $\mathrm{U}$ rich, and invariably contains three Us immediately after the hairpin. At least in vitro, termination efficiency is increased when nucleotide addition is slowed (Reynol ds and Chamberlin 1992; M cD owell et al. 1994; Wilson and von Hippel 1995) and by the presence of certain downstream DNA sequences if the $3^{\prime}$-proximal RNA is not mostly Us (Telesnitsky and Chamberlin
1989; Reynolds et al. 1992). It is likely that the U-rich 3'-proximal RN A and the downstream sequences, when important, cause transient backtracking of RNAP that allows proper timing of terminator hairpin formation and thus of a termination-prone complex (N udler et al. 1995; Landick 1997).

Pausing and termination may pass through a common paused intermediate (Chan et al. 1997; Landick 1997). Destabilization of the paused complex by invasion of the terminator hairpin closer to the RN A $3^{\prime}$ end and weak $\mathrm{rU} \cdot \mathrm{dA}$ base-pairing may favor transcript release, whereas a stable paused intermediate may allow escape back to the elongation pathway. In support of this hypothesis, the his pause signal can be converted into a weak terminator by base changes that extend the hairpin stem to $\leqslant 8$ nucleotides from the RNA $3^{\prime}$ end (the his perfect hairpin; Chan et al. 1997). Furthermore, some observations al so favor a role for direct interactions of terminator hai rpins with RNAP: (1) The sizes of stems ( $7 \pm 3 \mathrm{bp}$ ) and loops ( $4 \pm 1$ nucl eotides) in terminator hairpins are weakly conserved (d'Aubenton Carafa et al. 1990); (2) increasing stem length decreases termination in some cases (Wilson and von Hippel 1995); (3) certain sequences in terminator hairpins are weakly conserved (d'Aubenton Carafa et al. 1990); and (4) base substitutions that preserve base-pairing and predicted hairpin stability can reduce termination (Cheng et al. 1992). Alternatively (Fig. 1), a terminator hairpin could act indirectly by blocking backtracking of the TC (Komissarova and Kashlev 1997a; N udler et al. 1997), by disrupting the RNA-DN A hybrid (Yager and von Hippel 1991), or by blocking interaction of the nascent transcript with RN AP (Chamberlin 1995).

In principle, direct versus indirect mechanisms of nascent hairpin action can be distinguished by the effects of antisense RN A or DN A oligonucleotides that hybridize to the nascent transcript (Fig. 1). The indirect effect model predicts that an antisense oligonucleotide that leaves an 11-nucleotide 3'-proximal region should mimic the pause hairpin and stimulate pausing relative to other antisense oligonucleotides that are known to decrease pausing by destroying the hairpin (Fisher and Yanofsky 1983). Likewise, antisense oligonucleotides that invade to within 9 nucleotides of the $3^{\prime}$ end should stimulate termination, whereas others that disrupt the terminator hairpin should decrease it. On the other hand, if the RNA hairpin affects elongation directly through interaction with RNAP, no oligonucleotide should be able to substitute for a pause or terminator hairpin as its anneal ing to the hairpin would destroy the secondary structure. Yanofsky and co-workers showed more than a decade ago that antisense oligonucl eotides could inhibit either $\rho$-independent termination or hairpin-dependent pausing (Winkler et al. 1982; Fisher and Yanofsky 1983, 1984), but they could not easily conduct systematic experiments owing to the difficulty of obtaining ol igonucleotides at the time. The availability of oligonucleotides and recent reports that antisense oligonucleotides can inhibit transcriptional arrest (Reeder and Hawley 1996; Komissarova and Kashlev 1997a) encour- 
aged us to conduct the experiments reported here. Our results suggest that RNA hairpins play distinct roles in pausing and termination: a direct RNAP-RN A hairpin interaction is required to slow escape from the his pause site, but is dispensable for transcript rel ease from preformed paused complexes.

\section{Results}

Antisense oligonucleotide pairing to nascent RNA cannot stimulate pausing but can release transcripts from al ready paused complexes

To determine whether pairing of an optimal antisense ol igonucleoti de to the nascent RN A could substitute for the function of a nascent RNA hairpin in pausing or transcript release, we tested the effects of 22-mer antisense oligonucleotides whose $5^{\prime}$ ends approached the pause RNA $3^{\prime}$ end in one-nucleotide increments on the fraction of el ongating complexes that enters the paused state (pause efficiency), the rate of escape from the paused state (pause half-life), and tendency of the paused complex to dissociate (termination). We designated the antisense ol igonucl eotides by the length of nascent RN A remaining $3^{\prime}$ proximal to the antisense DNA-nascent RNA heteroduplex. For example, the $5^{\prime}$-most nucleotide of oligonucl eotide -11 hybridizes to the $3^{\prime}$-most $G$ in the pause hairpin (G-12, see Fig. 1) and leaves an 11-nucleotide 3'-proximal nascent RNA. We measured oligonucleotide effects on efficiency and half-life at $10 \mu \mathrm{m}$ GTP (the next nucleotide added at the pause site) after addition of oligonucleotides in 500-fold molar excess and then NTPs to halted elongation complexes that were formed at position A29 of the template (see Materials and $M$ ethods). $N$ one of the oligonucl eotides significantly altered pause efficiency, which we estimated to be $70 \pm 10 \%$ on this template (data not shown; see Wang et al. 1995; Landick et al. 1996, for description of pause efficiency). Oligonucleotides that paired far upstream from the RN A hairpin had no effect on pause half-life, whereas oligonucleotides that paired to bases within the pause hairpin decreased it by factors of up to 15 (e.g., 4 sec for -15 oligonucleotide vs. $\sim 60 \mathrm{sec}$ for -49 or no oligonucleotide; Fig. 2A,B). The large effect on half-life of oligonucleotides annealing to pause hairpin bases was relatively constant for oligonucleotides -11 to -27 , but gradually diminished as oligonucleotide $5^{\prime}$ ends were shifted further upstream. Importantly, even an antisense oligonucleotide that should create the same 11-nucleotide 3'-proximal RNA as the pause hairpin failed to stimulate pausing (oligonucleotide -11; Fig. 2B).

We confirmed that the DNA oligonucleotides hybridized to the RNA transcript where expected by assaying cleavage of the nascent transcript in the presence of oligonucleotides and RN ase $\mathrm{H}$, which cuts RN A only in an RNA-DNA hybrid (data not shown; RNA-template DN A base pairs within the TC are protected from RN ase $H$, presumably by steric exclusion). However, it was formally possible that the effects of oligonucleotides on pause half-life resulted from additional hybridization to

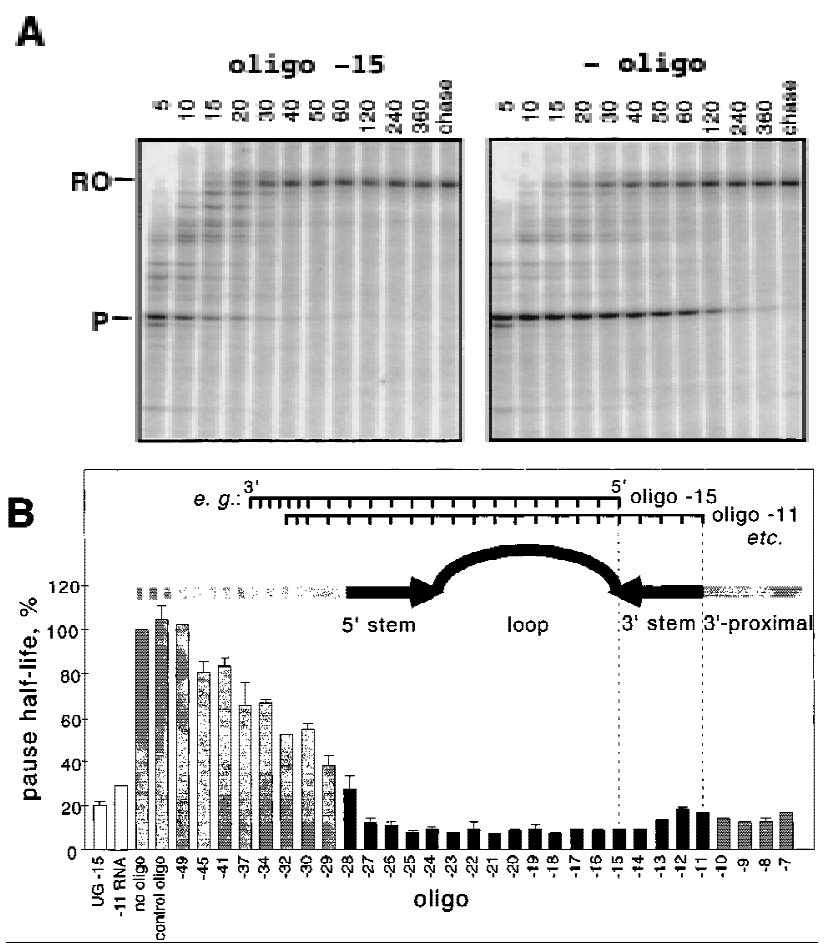

Figure 2. Effect of DNA oligonucleotides on the his pause halflife. (A) Preformed $\left[\alpha^{32}\right.$ P]CTP-labeled A29 complexes were chased with $10 \mu \mathrm{M}$ GTP, $150 \mu \mathrm{M}$ ATP, CTP, UTP in the presence (left) or absence (right) of the -15 ol igonucl eotide. Samples were taken at the times (in sec) indicated above each lane. The chase lanes contain samples that were incubated for an additional 5 min with $250 \mu \mathrm{M}$ each NTP after completion of the time course. (P) Pause RN A transcript; (RO) run-off RN A transcript. N onlinear regression yielded pseudo-first order half-lives of 5 and 60 $\mathrm{sec}$ for the -15-oligonucleotide and no oligonucl eotide experiments, respectively (see $M$ aterials and $M$ ethods). (B) Pause halflives were plotted (as a fraction of a 'no oligo' control from the same experiment) by the 5-most nucleotide of the nascent RN A that remains outside the RN A-oligonucleotide duplex (equivalent to the length of nascent RNA between the RNA-oligonucleotide duplex and the nascent RN A 3' end). Each value is an average of at least two independent measurements.

the nontemplate DNA strand, rather than to the RNA transcript. Such effects seemed unlikely to explain all our results because some oligonucleotides that reduced the pause half-life annealed entirely upstream from the regi on corresponding to the $\sim 17$-bp transcription bubble (i.e., oligonucleotides whose $5^{\prime}$ ends are more that 15 nucleotides from RN A 3' end, the typical upstream end of the transcription bubble, Fig. 2B; see Gamper and Hearst 1982; Lee and Landick 1992; Zaychikov et al. 1995, for transcription bubble measurements). To confirm this interpretation, we adopted the approach of Reeder and Hawley (1996) and tested an 18-nucleotide DNA oligonucleotide that could anneal to RNA but not DN A because it contained $G$ s opposite the $8 \mathrm{U}$ s between nucleotides -33 and -16 (UG-15, Fig. 2B; see Materials and $M$ ethods). This oligonucleotide reduced the pause half-life by a factor of 5, consi stent with the weaker pair- 
ing expected relative to the A-containing -15 oligonucleotide and supportive of the conclusion that antisense oligonucleotides reduce pausing by disrupting the pause RN A hairpin.

Oligonucleotides whose pairing extended past the pause hairpin to within the 7- to 9-nucleotide 3 '-proximal region characteristic of $\rho$-independent terminators still reduced pausing, but did not terminate transcription (e. g., -7 ol igonucl eotide; Fig. 3A), even at concentrations of $\mathrm{KCl}(\geqslant 0.5 \mathrm{M})$ that allow weak termination when the pause hai rpin stem is extended to within this region (the 'perfect hairpin' pause site; Chan and Landick 1997). However, we could not conclude from this result that direct hairpin RNAP interaction is also required for termination because pausing could be an obligatory step in the termination pathway. Thus, the strong inhibition of pausing caused by antisense ol igonucleotides itsel $f$ could prevent termination.

Therefore, we tested the effects of oligonucl eotides on preformed paused TCs. We formed paused TCs from A29 complexes immobilized on beads by repeated rounds of stepwise transcription (Wang et al. 1995; Kashlev et al. 1996), and then tested whether oligonucleotides that could invade the 7- to 9-nucleotide 3'-proximal region could terminate transcription at $1 \mathrm{M} \mathrm{KCl}$. Initially we tested for extention of the pause RNA after incubation of paused TCs with the ol igonucleotides. Oligonucleotides that annealed $\geqslant 9$ nucleotides from the RNA $3^{\prime}$ end re- duced the pause half-life by the same factor of $~ 10$ observed when they were present as TCs elongating through the pause site (e.g., oligonucleotide -10; Fig. 3A; note that incubation of the -11 oligonucleotide, not shown, with paused TCs still did not stimulate pausing). The small amount $(\sim 20 \%)$ of pause RN A that failed to extend when oligonucl eotides annealing $\geqslant 9$ nucl eotides from the RNA $3^{\prime}$ end were added was attributable to partial inactivation of the paused TC during its preparation, as the same fraction al so failed to extend after addition of a noncomplementary oligonucleotide or of no oligonucleotide. However, oligonucleotides that could hybridize to within 8 nucleotides or less of the pause RNA $3^{\prime}$ end prevented extension of $65 \%$ of the pause RNA when they were added either $5 \mathrm{~min}$ before or together with $150 \mu$ м NTPs (e.g., -7 oligonucleotide; Fig. $3 A)$.

To determine whether the pause RNA that failed to extend in the presence of the $-7,-5$, and -3 oligonucl eotides was trapped in arrested TCs or was actually released, we separated and analyzed the supernatant and bead fractions of the transcription reactions (Fig. 3B). Oligonucleotides $-7,-5$, and -3 released about fivefold more pause RNA ( $50 \%$ of the starting sample) than oligonucleotides $-8,-9$, or the control oligonucleotide ( $10 \%$ of the starting sample). Thus, all three antisense ol igonucleoti des that could pai $r$ to the base 8 nucl eotides from the pause RN A 3' end stimulated transcript release
A

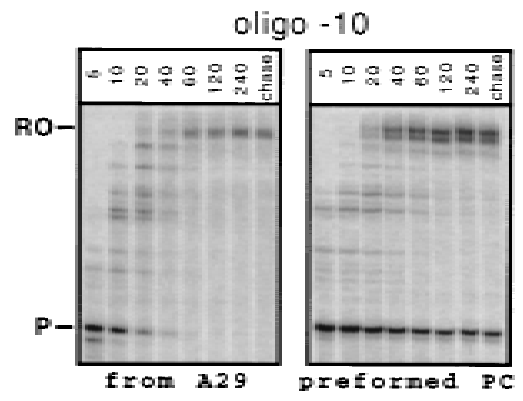

B

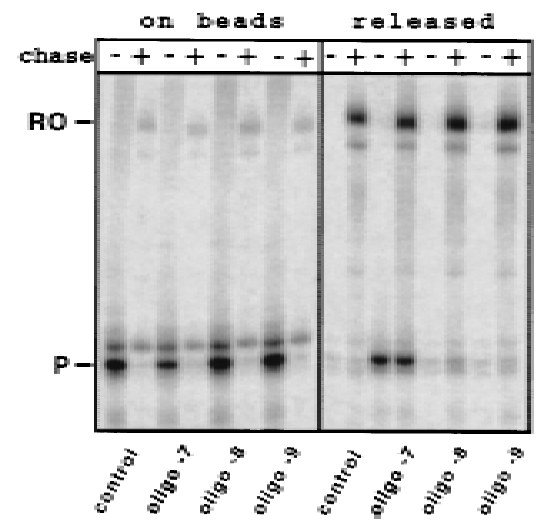

oligo -7
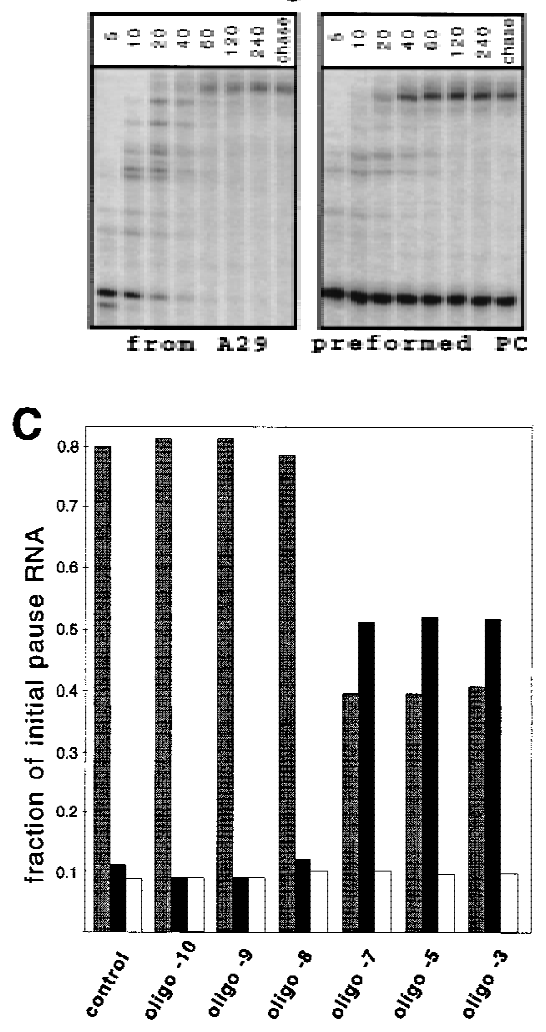

Figure 3. Transcript release by antisense oligonucleotides. (A) A29 complexes or preformed paused complexes were eluted from the beads (see Materials and Methods) and incubated for $5 \mathrm{~min}$ in the presence of either the -10 or -7 oligonucleotide. Elongation was allowed to resume in the presence of $1 \mathrm{M}$ $\mathrm{KCl}$ by addition of NTPs and samples were taken at the times indicated above each lane. (B) Preformed paused complexes were left on beads, incubated with 500 -fold excess of each oligonucleotide in $1 \mathrm{M} \mathrm{KCl}$, and chased with NTPs. The supernatants (rel eased RN A) and the beads (RNA remaining in TCs) from samples before and after the chase were collected and electrophoresed separately. (C) Relative concentrations of pause RNA that was extended (shaded bars) released from TCs (solid bars), or retained on beads (open bars) after addition of NTPs to the preformed paused complexes were determined from Phosphorlmager scans and are plotted as a fraction of the total pause RNA. 
from preformed paused complexes to the same extent. The need to preform paused complexes to observe release is unl ikely to reflect an inability of the oligonucleotides to hybridize rapidly enough to affect a moving RNAP, as ol igonucleotides were able to reduce the pause half-life while RN AP is moving. Furthermore, we did not observe RNA release at the pause site when the complexes were walked to positions -7 or -2 , incubated with -7 oligonucleotide to allow time for hybridization, and then chased (data not shown). These results suggest both that oligonucl eotide-stimulated release requires preexistence of the paused complex and that release does not occur at template positions $(-7$ and -2$)$ that do not form paused complexes, even when oligonucleotides can hybridize to the base 8 nucleotides from the transcript 3' end.

From these experiments with antisense oligonucleotides we concluded tentatively that pausing requires direct interaction of a nascent hairpin structure with RNAP, but that once a paused TC is formed, transcript release requires only indirect disruption of the -8 nucleotide's interactions with RNAP or with the DNA template. Importantly, the -8 nucleoti de appears to form the upstream most base-pair in the TC RNA-DN A heteroduplex (Lee and Landick 1992; N udler et al. 1997; see Discussion).

The structure and geometry of the pause hairpin in the nascent RNA is essential for its function

Although the results described so far suggested that the nascent pause RN A hai rpin makes relatively specific and functionally important contact to RNAP, it remained possible that indirect effects of the hairpin could not be recapitulated by less stable DNA-to-RN A base-pairing, that oligonucleotide pairing to the transcript could stimulate pausing if it also presented a suitably located single-stranded loop to interact with RN AP, or that the hairpin might not need to be anchored to the nascent RNA at all. To test these possibilities, we used RNA oligonucleotides that could form an RNA-RNA duplex in place of the wild-type pause hairpin (RNA1), that could form an RNA-RN A duplex with a single-stranded loop where the pause hairpin loop normal ly would occur (RN A2), or that could form the pause hairpin structure free in solution (RNA3). We tested RNA oligonucleotides on both a wild-type template (WT, Fig. 4A) and a template that specified a mutant pause hairpin that contains three mismatches in the hairpin stem (MS hairpin, Fig. 4B; Chan and Landick 1993; Wang et al. 1995). The MS hairpin appears to be stabilized partially by interaction with RN AP; therefore, it reduces but does not eliminate pausing (Wang and Landick 1997). Thus, it allowed us to test for either inhibition or stimulation of pausing by RN A3, which could hypothetical ly either competefor or mimic the effect of a nascent RNA hairpin (stimulation of pausing could be indistinguishable from no effect of the oligonucleotide on the wild-type template).

Ternary complexes were walked by successive rounds of elongation with NTP subsets to the -7 position of
A
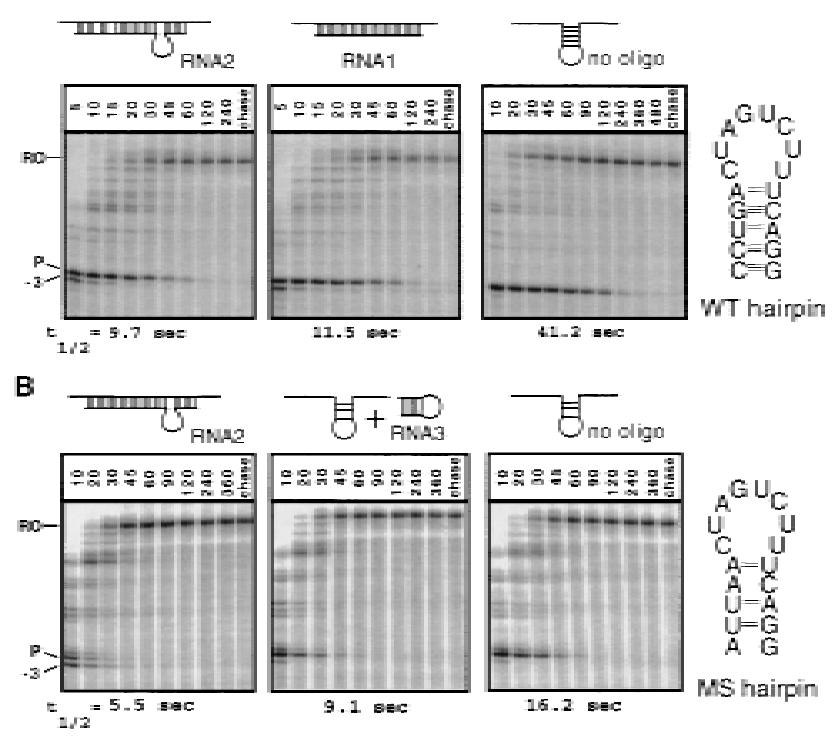

Figure 4. Effect of RNA oligonucleotides on pausing on the wild-type (WT; A) and multisubstituted (MS; B) hairpin templates. A29 complexes were walked to the -7 (U64) position, incubated in the presence or absence of oligonucleotide, and then chased (see M aterials and M ethods). RN A 1 is complementary to the WT pause hairpin (CCUGAAAGACUAGUCAGGAUGA), RNA2 oligonucleotide is complementary to the MS hairpin and contains the 7-nucleotide insertion of the trp hairpin loop sequence (underlined; CCUGACUAAUGAAAGACUAGUUAAUAUGA); for both RNA1 and RNA2 oligonucleotides the $5^{\prime}$ end is positioned at -11 . RNA3 oligonucleotide corresponds to the his pause hairpin (CCUGACUAGUCUUUCAGG). Structures predicted to form with annealing of oligonucleotides to the RNA transcript are shown schematically above each lane. Cal culated pause half-lives are indicated bel ow each panel.

both templates, incubated with 500-fold molar excess of RNA oligonucleotides to allow formation of RN A-RN A hybrids, and then chased at limiting GTP (10 $\mu \mathrm{M})$. On both templates, addition of RNA1 or RNA 2 reduced the half-life by a factor of 3 to 4 (Fig. 4A,B). The effects of RNA oligonucleotides on pausing are less than those of the DN A oligonucleotides, most likely because the formation of hairpin structures in the RNA oligonucleotides competes with antisense oligonucleotide-nascent RNA pairing. The addition of the pause RN A hairpin as a separate molecule (RNA3) reduced pausing slightly on the MS hairpin template (Fig. 4B), but not on the WT template (data not shown). The slight inhibition on the MS template may reflect competition by RNA3 for the interaction of the MS hairpin with RNAP, but it might also be explained by direct disruption of the weak MS hairpin structure by pairing of complementary bases in RNA3.

From these results we conclude that neither $20 \mu \mathrm{m}$ RNA hairpin in trans nor an RN A-RN A duplex that creates the proper $3^{\prime}$-proximal spacing in conjunction with a properly positioned loop sequence is sufficient to 
stimulate pausing in the manner observed for a nascent RNA hairpin. Thus, the pause hairpin structure must be present in the nascent RNA and makes contacts that depend on its precise location and structure.

Antisense oligonucleotides mimic disruption of pause hairpin interaction with RNAP

If antisense oligonucleotides affect pausing solely by pairing to the nascent RNA (rather than to the nontemplate DNA or through interactions with RNAP), their effects should be reduced under conditions that compromise the pause hairpin interaction because previous results have establ ished that the effect of the pause hairpin on half-life is additive with other interactions (Chan et al. 1997). Thus, to test our conclusions further, we analyzed the effects of antisense oligonucleotides on pausing when IMP was substituted for GMP in the pause hairpin and in the presence of elevated $\left[\mathrm{Cl}^{-}\right]$.

Substitution of IMP for GMP in the hairpin stem should destabilize it by $\sim 4 \mathrm{Kcal} /$ mole by reducing the number of hydrogen bonds $(\sim 1.3 \mathrm{Kcal} / \mathrm{mole}$ per substitution; SantaLuca et al. 1992) and replacing GTP with ITP in transcription reactions is known to inhibit some pauses (Reisbig and Hearst 1981; Levin and Chamberlin 1987). By stepwise transcription, we substituted IMP residues only for the three Gs in the his pause hairpin and then measured the pause half-life in the absence and presence of an antisense DNA oligonucleotide (Fig. $5 A, B)$. Substitution of IMP in the hairpin stem reduced the half-life by a factor of $\sim 4$ (from 97 to $27 \mathrm{sec}$ ) in the absence of DNA oligonucleotide. Addition of oligonucleoti de further decreased the half-life to $9 \mathrm{sec}$ on both templates, therefore destabilization of the hairpin with IMP reduced the oligonucleotide effect to a factor of 3 rather than by a factor of 12 . These results and those with the MS hairpin (Fig. 4; see above) show that although either IMP substitution or base mismatches in the hairpin stem reduce pausing by destabilizing the structure, nei ther eliminates compl etely the hairpin's effect on pausing. Importantly, in both cases, antisense oligonucleotides reduce the pause half-life only to the same half-life they produce on a wild-type template, rather than by the same factor as would be expected if they affected pause escape through interactions other than with the nascent RN A.

Elevated concentrations of $\mathrm{KCl}$ decrease the rate of elongation at most template positions, but increase the rate of escape from the his pause site apparently by blocking hairpin interaction, leading to a net decrease in the pause half-life by a factor of 3 at $1 \mathrm{~m} \mathrm{KCl}$ (Chan and Landick 1997). If this idea is correct, elevating $\mathrm{KCl}$ concentration and adding an oligonucleotide complementary to the hai rpin should not produce synergistic effects on pause half-life, as both are predicted to eliminate pause hai rpin-RNAP interaction. We tested this prediction by measuring the half-life of the paused complex in the presence of DNA oligonucleotide at low salt or at 1 $\mathrm{M} \mathrm{KCl}$ (Fig. 5C). As expected, the combination of oligonucleotide and $\mathrm{Cl}^{-}$did not reduce pause half-life any
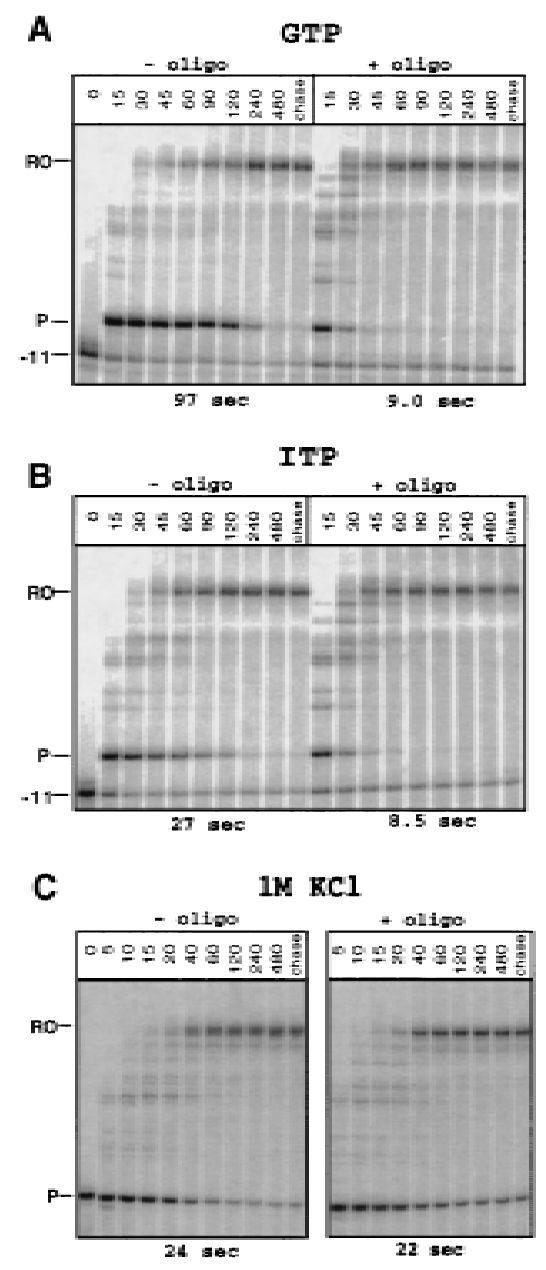

Figure 5. Effect of DNA oligonucleotides on pausing on templates with hairpins destabilized by ITP substitution within the stem or $\mathrm{KCl}$ addition. $A 29$ complexes were walked to the -11 $(G 60)$ position $(A, B)$ or to the pause site $(U 71, C)$. Either GTP (A) or ITP (B) was incorporated at three positions within the hairpin stem (see Fig. 1). Complexes were eluted from the beads and incubated at $37^{\circ} \mathrm{C}$ for $5 \mathrm{~min}$ in the absence or presence of oligonucleotide -15 , and, in $\mathrm{C}$, at $1 \mathrm{M} \mathrm{KCl}$. Elongation was resumed and samples were analyzed as above. Half-lives determined as described in M aterials and M ethods are shown below each panel.

further than $\mathrm{Cl}^{-}$alone, even though el evated $\mathrm{KCl}$ should promote anti sense ol igonucleotide pai ring to the nascent RN A. Importantly, this result confirms that el evated $\mathrm{Cl}^{-}$ alone can eliminate the effect of the pause hairpin and that its 3-fold rather than the $>10$-fol d effect reflects the general sl owing of RNA chain el ongation at elevated $\mathrm{Cl}^{-}$.

The pause hairpin inhibits nucleotide addition by disengaging the RNA 3' end from the active site

Finally, we wished to use antisense oligonucleotides to test the idea that the pause hairpin functions by disengaging the RN A 3' end from the active site (e.g., by hypertranslocation; see Fig. 6 and Chan et al. 1997) rather 
than by causing backtracking of RNAP along the template as has been proposed for some pause sites (Guajardo and Sousa 1997; Komi ssarova and Kashl ev 1997b; N udler et al. 1997). Backtracking of RNAP may precede both $\rho$-independent termination and formation of a hairpinstabilized paused TC (Nudler et al. 1995; Wang et al. 1995; Landick 1997); extensi ve backtracking can lead to transcription arrest (Reeder and Hawley 1996; Komissarova and Kashlev 1997a). However, the resistance of the his paused complex to GreA-stimulated transcript cleavage (Feng et al. 1994) argues against backtracking in the hairpin-stabilized paused TC because GreA stimulates cleavage of 2- to 3-nucleotide fragments from the $3^{\prime}$ end when RNAP is backtracked (Borukhov et al. 1993). N onetheless, it remained formal ly possible that RN AP is backtracked by only 1 nucleotide at the his pause site and therefore, does not serve as a substrate for cleavage. If this were the case, then the pause RNA should be susceptible to pyrophosphorolysis. Furthermore, if backtracking occurred, antisense oligonucleotide pairing might inhibit pyrophosphorolysis at the pause as it does transcript cleavage at an arrest site (Reeder and Hawley 1996; Komissarova and Kashlev 1997a). In contrast, if hypertranslocation occurred, antisense oligonucleotide pairing might actually promote pyrophosphorolysis.

We tested compl exes hal ted at the pause and at several positions before the pause, $-7,-2$, and -1 , for their sensitivity to pyrophosphate ( $\mathrm{PP}_{\mathrm{i}}$; Fig. 6). The paused complex was resistant to $\mathrm{PP}_{\mathrm{i}}$ at all concentrations tested (up to $1 \mathrm{~mm}$; Fig. $6 \mathrm{E}$ ), whereas complexes halted at positions $-7 \mathrm{U},-2 \mathrm{G}$, and $-1 \mathrm{C}$ were all sensitive, al though to different extents (Fig. 6A,B,D). Complexes with a $U$ at the transcript 3' end were unusually sensitive to pyrophosphorolysis: the -7 RN A was shortened by 1 nucleotide at $1 \mu \mathrm{M} \mathrm{PP}_{\mathrm{i}}$ (Fig. 6A), and RNAs corresponding to $-3 \mathrm{U},-5 \mathrm{U}$ were cleaved too rapidly to be detected during degrada- tion of $-2 \mathrm{C}$ and $-1 \mathrm{G}$ complexes (Fig. 6B,C). Therefore, the conformation of the $\mathrm{PP}_{\mathrm{i}}$-resistant, his paused complex must be different from other complexes with a 3'terminal UMP. We interpret this $\mathrm{PP}_{\mathrm{i}}$ resistance to mean that the pause hairpin prevents backtracking even by 1 nucleotide to the $\mathrm{PP}_{\mathrm{i}}$ senstitive, pretranslocated conformation and most likely favors the hypertranslocated conformation (Fig. 6). In agreement with this conclusion, addition of the -18 antisense oligonucleotide that destroys the pause hairpin stimulated pyrophosphorolysis (Fig. 6F), whereas an oligonucleotide that pairs upstream from the pause hairpin had no effect (Fig. 6H). The -11 antisense oligonucleotide, which can create the same 3'proximal spacing as the pause hairpin but could not stimulate pausing (see Fig. 2), also could not recapitulate the $P P_{i}$ resistance caused by the wild-type pause hairpin (Fig. 6G). Thus, direct hairpin interaction with RNAP appears to be required to prevent pyrophosphorolysis as well as to stimulate transcriptional pausing.

Finally, if our hypothesis that $\mathrm{Cl}^{-}$ion inhibits pause hairpin-RN AP interaction is correct and this interaction is required to disengage the $3^{\prime} \mathrm{OH}$ from the active site, then $\geqslant 0.5 \mathrm{M} \mathrm{KCl}$ should stimulate pyrophosphorol ysis in the his paused TC (see Fig. 5; Chan and Landick 1997). In confirmation of this prediction, we found that $1 \mathrm{M} \mathrm{KCl}$ stimulated pyrophosphorolysis of the his pause RNA (Fig. 6I), but had no effect at the -2 position (Fig. 6C) and slightly inhibited pyrophosphorolysis caused by addition of the -18 oligonucl eotide to the paused TC (cf. Fig. 6F, J). Similar effects were observed with $0.5 \mathrm{~m} \mathrm{KCl}$ (data not shown). We conclude that, in the his paused TC, direct interaction of the pause hairpin with RNAP inhibits nucleotide addition and pyrophosphorolysis by moving the RNA 3' OH away from the NTP-binding subsite, most likely to a hypertranslocated state, rather than by favoring backtracking of RNAP.
Figure 6. Transcript sensitivity to pyrophosphorolysis. (Top) Different conformations of TC can be distinguished by their sensitivity to transcript cleavage and pyrophosphorolysis. (Bottom) Immobilized TCs were hal ted al ong the template encoding the WT his pause signal at the positions indicated below each panel and treated with increasing concentrations of $\mathrm{PP}_{\mathrm{i}}$ (indicated above each panel; see $M$ aterials and $M$ ethods). Oligonucleotides, $1 \mathrm{M} \mathrm{KCl}$, or both were added when indicated.
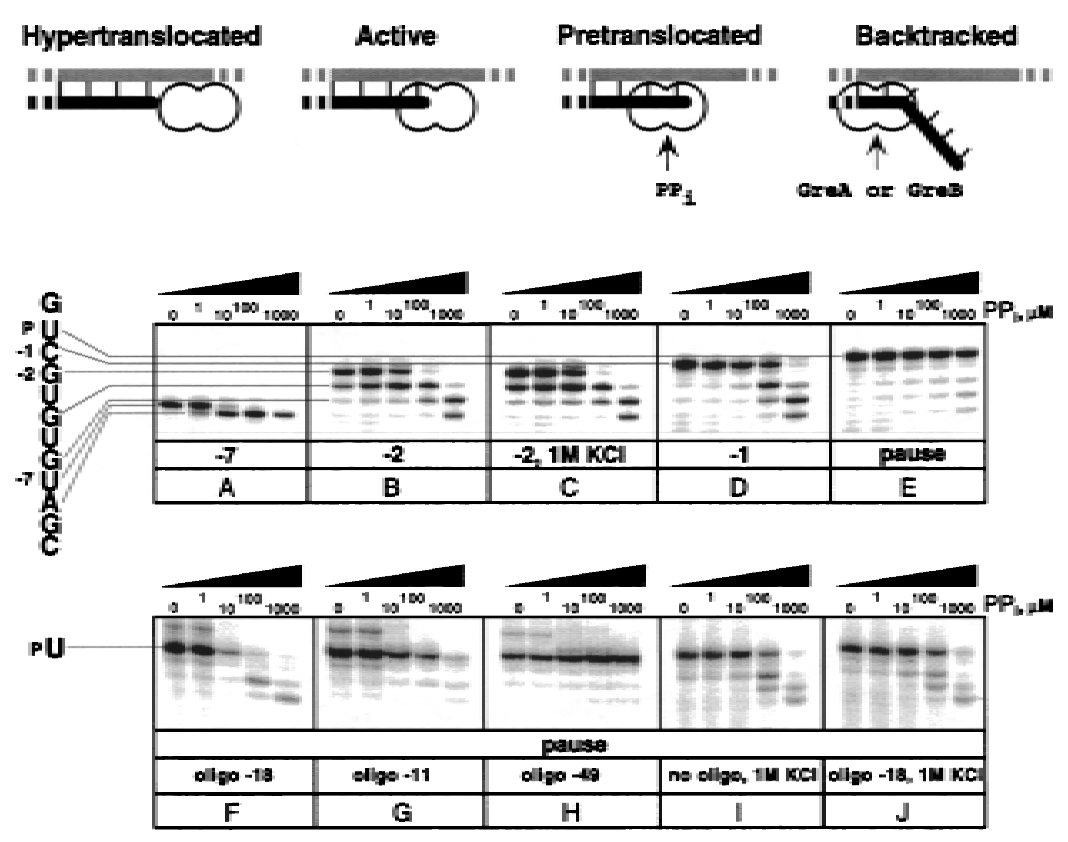


\section{Discussion}

The principal conclusion of our study is that nascent RNA structures stimulate transcriptional pausing or transcript release through different types of interactions with the TC. At the pause site, a nascent RNA hairpin inhibits nucl eotide addition through a direct interaction with RNAP that cannot be mimicked by structures formed with antisense RN A or DNA oligonucleotides. In contrast, antisense oligonucleotides can stimulate transcript release, provided that RNAP is not locked in a cycle of rapid chain extension. This suggests that terminator hai rpins could act indirectly simply by disrupting interaction of SSRNA with RNAP or template DNA. In addition, our results argue that interaction of the his pause RN A hairpin with RNAP blocks nucleotide addition by disrupting contact between the active site and the nascent RNA. We will discuss these conclusions in the context of a current model for RN A chain elongation and termination.

Antisense oligonucleotides may affect different steps in transcript elongation

Rapid chain elongation occurs in the bipartite active site of RN AP in a cycle of at least four steps: (1) NTP binding in subsite $\mathrm{i}+1$; (2) nucleophilic displacement of the NTP's pyrophosphate by the transcript's $3^{\prime} \mathrm{OH}$, which is positioned in subsite i; (3) pyrophosphate rel ease; and (4) translocation of the new 3'-terminal nucleotide back to subsite i (Fig. 7, DN A omitted for clarity; see Erie et al. 1992). Transcriptional pausing, termination, or arrest, al I events that interrupt chain elongation, appear to begin with transient backtracking of RNAP along the RNA and DNA chains, which removes RN AP from the rapid cycle of chain extension (N udler et al. 1995, 1997; Wang et al. 1995; Reeder and Hawley 1996; Komissarova and Kashlev 1997a,b; Landick 1997). Backtracking, also called reverse translocation, means that both the RN ADN A hybrid and RN AP contacts to RNA and DN A slide upstream by a few nucleotides so that the active site becomes occluded by the RNA chain. This prevents nucleotide addition, but allows transcript cleavage. Backtracking is thought to be triggered at sequences for which the RN A-DN A hybrid and RN AP-DN A contacts in the active conformation (with site $i+1$ open) are less stable than those formed when RNAP shifts upstream. This transient movement may slow nucleotide addition for a length of time that depends on the 'positional equilibrium' among the active conformation and the nearby backtracked states (Guajardo and Sousa 1997; Komissarova and Kashlev 1997b; Landick 1997; Nudler et al. 1997); thus unstable RN A-DN A and RN A P-nucleic acid contacts may generate one type of transcriptional pausing.

Once backtracking has disrupted the cycle of rapid NTP addition and $\mathrm{PP}_{\mathrm{i}}$ release, a second rearrangement may lead to transcriptional arrest, to hairpin-dependent pausing, or to termination depending on RNA and DNA sequences and structures that surround the 10- to 12 -

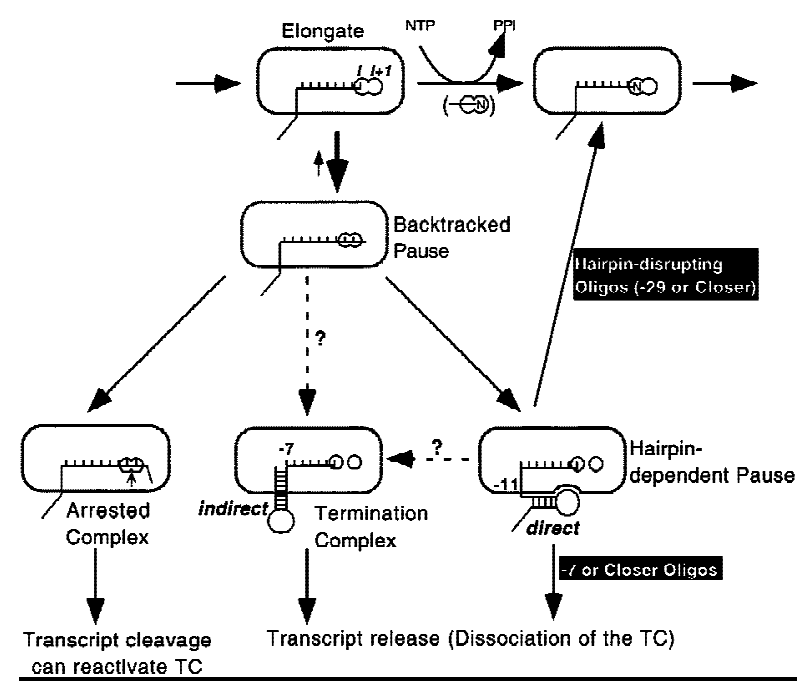

Figure 7. M odel of events that interrupt RN A chain el ongation and the effects of antisense oligonucl eotides on them. The steps in rapid chain el ongation (see text) are represented horizontally at the top. RN AP in an el ongating TC is represented by the oval; the DNA strands were omitted for clarity. RNAP's bipartite active site is represented by the double circle (modified from Erie et al. 1992 to use i for the binding site of the $3^{\prime}$-terminal nucleotide and $i+1$ for the binding site of the incoming NTP). Transcript bases that are paired to the DN A template are shown by vertical lines; other transcript bases are not shown (the RN Ato-DN A hybrid is thought to be $\sim 8 \mathrm{bp}$; see Lee and Landick 1992; Landick 1997; N udler et al. 1997, and references therein). This model of hairpin-dependent pausing and $\rho$-independent termination differs superficially from other versions we have published recently (Chan et al. 1997; Landick 1997; Mooney et al. 1998) because it shows the backtracked pause as a separate intermediate to illustrate the possibility that, at least for some $\rho$-independent terminators, RNAP-RNA hairpin interaction may not be essential for transcript release.

nucleotide $3^{\prime}$-proximal region (Fig. 7). If the transcript lacks structures that block further backtracking, then further retreat of the TC may extrude enough of the 3' region of transcript to form a stable structure or an association with RNAP that arrests transcription until it can be reactivated by transcript cleavage. If a hairpin can form 10-12 nucleotides from the RN A 3 ' end, then it may stabilize a hairpin-dependent paused conformation. Finally, if the hairpin can reach to within 7-9 nucleotides of the $3^{\prime}$ end, then the TC is destabilized and, if the remaining 3'-proximal RNA is U-rich, may dissociate even at low salt (intrinsic termination).

Direct contact between the pause hairpin and RNAP disrupts association of the transcript with the active site at the his pause site

Previous results, including cross-linking of the pause hairpin to $\beta$ subunit residues 904-950 (Wang and Landick 1997) and inhibition by $\mathrm{Cl}^{-}$ion of only the hairpindependent component of transcriptional pausing (Chan and Landick 1997), suggested that the contribution of the 
pause hairpin to inhibition of nucleotide addition at the his pause site was mediated through a direct interaction with RN AP. However, it is difficult to rule out the possibility that hairpin cross-linking to RNAP simply reflects its proximity to the enzyme, rather than a functional interaction. Furthermore, the $\mathrm{Cl}^{-}$effect is potentially complex. Although the threefold acceleration of nucleotide addition at the pause that is caused by $\mathrm{Cl}^{-}$ almost certainly involves the pause hairpin (Chan and Landick 1997), as only substitutions in the pause hairpin and not the other pause signal components reverse the $\mathrm{Cl}^{-}$effect, it is possible that binding of $\mathrm{Cl}^{-}$supplants interactions of single-stranded transcript with RNAP that facilitate chain el ongation and that are disrupted by the pause hairpin. Furthermore, $\mathrm{Cl}^{-}$is a competitor of many protein-DN A interactions (Leirmo et al. 1987) and thus may also compete for stabilizing interactions of the nontemplate or template DNA strands with RN AP (see below).

Our finding that antisense RN A or DN A oligonucleotides are unable to substitute for the effect of the pause hairpin provides important confirmation for the ideas that pause hairpin function requires a specific interaction with RNAP and that this interaction can be disrupted by $\mathrm{Cl}^{-}$binding to RNAP. The following key points establish these conclusions. First, all antisense oligonucleotides that can disrupt the pause hairpin reduce the pause half-life by a factor of $\sim 15$, even when they should recapitulate the same 3 '-proximal spacing as the pause hairpin (Fig. 2B). Thus, the increase in pause half-life caused by the pause hairpin must be $\sim 15$-fold, higher than the 6- to 10-fold estimated from base substitutions (Chan and Landick 1993). Second, neither addition of the pause hairpin RN A as a separate molecule at high concentration, nor pairing to the transcript of antisense oligonucleotides that should recreate the pause hairpin loop were able to substitute for the wild-type pause hairpin in the nascent RNA (Fig. 4). Third, oligonucleotide effects were reduced when the pause hairpin contained natural or inosine base substitutions, but not when the antisense oligonucleotides contained Gs that should pair to RN A but not DN A (Figs. 2, 4, and 5). Thus, the effects of oligonucl eotides clearly were through pairing to the nascent RN A and not the nontemplate DNA. Fourth, the ability of $\mathrm{Cl}^{-}$to accelerate escape from the pause was el iminated by antisense oligonucl eotides (Fig. 5). This argues strongly that both $\mathrm{Cl}^{-}$and antisense oligonucleotides accelerate nucleotide addition at the pause by competing for RN A hairpin-RN AP interaction. Finally, both antisense oligonucleotides and $\mathrm{Cl}^{-}$ion are able to ameliorate the unusual resistance of the paused complex to pyrophosphorolysis (Fig. 6). Thus, interaction of the pause hairpin with RN AP, which can be disrupted by either antisense oligonucleotides or $\mathrm{Cl}^{-}$, must disengage the nascent RNA $3^{\prime} \mathrm{OH}$ from reactive alignment in the active site. Backtracking by one or more nucleoti de as an explanation for hairpin-dependent pausing is ruled out by the paused complex's resistance to both pyrophosphorolysis (Fig. 6) and transcript cleavage (Feng et al. 1994).
Therefore, we propose that direct RN A hairpin-RN AP interaction is an integral component of the mechanism of transcriptional pausing at the his pause site and that it stabilizes a conformation of the TC that is different than a backtracked TC. This conformation most likely is hypertranslocated, with the RNA $3^{\prime}$ end displaced upstream from its normal position, whereas interaction of RNAP with the downstream DNA, which also is requi red for strong pausing (Lee and Landick 1992; Wang et al. 1995), may anchor the front end of the enzyme on the template and prevent the NTP-binding subsite from moving with the pause RN A $3^{\prime}$ end. Most nascent RN A contacts in the active site could be retained in the paused conformation, however, as separating the $3^{\prime} \mathrm{OH}^{-}$and NTP-binding subsites $i$ and $i+1$ by only a few tenths of an angstrom should be sufficient to inhibit nucleotide addition.

An important implication of these findings is the existence of at least two types of paused transcription complexes. Hairpin-dependent pauses disrupt the transcriptactive site association and require hairpin-RN AP interaction. Backtracked pauses, which set up formation of the hairpin-dependent pause, may in some cases create strong delays in transcript elongation by occluding the i +1 site with nascent RNA (for instance, a strong backtracked pause occurs in the early transcribed regi on HIV1; see Palangat et al. 1998). Whether pause hairpinRNAP interaction simply provides the free energy required to pull the RNA $3^{\prime}$ end out of the active site, causes a direct al losteric change in RN AP that al ters the active site, or possibly creates a physical barrier to binding of NTP or $\mathrm{PP}_{\mathrm{i}}$ substrates into the active site remain questions for future study.

\section{Role of RNA hairpin in transcription termination}

Our results also have important implications for the mechanism of $\rho$-independent termination. First, because we were able to observe transcript release only when antisense oligonucleotides were added to preformed paused $\mathrm{TCS}$, and not when they were present during elongation and thus counteracted pausing (Fig. 3), our results support the generally held view that pausing of some type must precede transcript release (Farnham and Platt 1980; von Hippel and Yager 1991; McDowell et al. 1994). However, although transcript release clearly can occur from a hairpin-dependent paused complex, wecannot exclude the possibility that formation of a terminator hairpin could release the transcript from a backtracked pause and not require the hairpin-RNAP interaction present in the hairpin-dependent paused complex (Fig. 7). Because intrinsic terminators are typically $U$ rich after the hairpin, they encode strong signals for backtracking, which has been observed at least for $\lambda t_{R 2}$ (Nudler et al. 1995). The backtracked pause formed at the his pause site may not delay RNAP sufficiently for oligonucleotide-mediated transcript release. Although one might argue that the requirement for $1 \mathrm{M} \mathrm{KCl}$ to observe oligonucleotide-mediated release in our experiments as well as transcription termination when the 
pause hai rpin stem is extended to within 9 nucleoti des of the RNA end reflects a need to di srupt a stabilizing hairpin interaction with RN AP, both antisense oligonucleotides and the perfect hairpin al ready disrupt this interaction at low salt. Thus, the requirement for high salt to observe transcript release at the pause more likely reflects $\mathrm{Cl}^{-}$displacement of an RNAP-RNA or RNAPDNA interaction, such as with the nontemplate strand, that is compromised by the $\mathrm{U}$-rich $3^{\prime}$-proximal region at a $\rho$-independent terminator (see below).

The second important implication of our results for the mechanism of termination derives from the remarkably narrow window of spacing from the RNA 3 ' end within which antisense oligonucleotide pairing stimulates transcript release. Only when an antisense oligonucleotide pairs to the -8 nucleotide did we observe re lease, and the efficiency of release was unchanged when pairing closer to the $3^{\prime}$ end was possible (Fig. 3; cf. effects of $-8,-7,-5$, and -3 oligonucl eotides). Presumably pairing to the -8 nucleotide reflects disruption of an interaction critical for TC stability, which is accomplished at an intrinsic terminator by the terminator hairpin. There are at least three such interactions whose loss could be a critical step in intrinsic termination. The first is pairing of the nascent RNA to the DNA template, whose thermodynamic contribution to TC stability near a terminati on site may depend on backtracking of RN AP. Because backtracking appears to compensate energetically for the unstable $\mathrm{rU} \cdot \mathrm{dA}$ base-pairs produced at a terminator, the possible oscillation of the TC among different positional conformers may keep the TC stable until backtracking is prevented by formation of the terminator hai rpin. Restricting the positional equilibrium of the TC to an unstable hybrid might then cause transcript release. Antisense oligonucleotides have been shown to prevent backtracking of RN AP (Reeder and Hawley 1996; Komissarova and Kashlev 1997a), therefore they al so could produce this effect.

The second possibility is a related idea originally postulated by Yager and von Hippel (1991), who argued that pairing of nascent RNA to the DNA template compensated energetically for formation of the single-stranded transcription bubble and that transcript release occurs when a terminator hairpin shortens the RN A-DN A heteroduplex (postulated then to be $12 \mathrm{bp}$ ) because the remaining $\mathrm{rU} \cdot \mathrm{dA}$ base-pairs are too weak to prevent collapse of the transcription bubble. Thus, antisense oligonucleotide pairing to the -8 nucleotide might allow nontemplate-template strand pairing at a critical positi on that would lead to complete bubble collapse because the remaining bubble is too short to be stabilized by RNAP.

The third possibility, originally suggested by Chamberlin and co-workers (Reynolds et al. 1992; Chamberlin 1995), is that ssRN A interaction with RNAP stabilizes the TC, which becomes unstable when a terminator hairpin disrupts the ssRNA-RNAP interaction. This idea was el aborated further by Nudler et al. $(1996,1997)$ who suggested that terminator hairpins may disrupt critical RNAP-sSRNA interactions in the transcript exit channel that could help keep RNAP wrapped tightly around the downstream DNA duplex. Antisense oligonucleotide pairing similarly could disrupt these interactions and produce transcript release.

These three possibilities are not mutually exclusive. Antisense oligonucleotides may destabilize the TC by causing more than one of these effects and our results do not distinguish among them unambiguously. However, the critical role of antisense oligonucleotide pairing to the -8 nucleotide leads us to suggest that competition between RNA-DNA base pairing and transcripition bubble coll apse deserves more careful consi deration than it has received recently. Both the Chamberl in and Goldfarb groups have argued that RNA-DNA base pairing cannot be responsible for the resistance of the TC to dissociation (Chamberlin 1995; N udler et al. 1996; Uptain and Chamberlin 1997). However, some evidence central to this conclusion relies on studies of TCs that lack a nontemplate strand in the critical region 7-10 nucleotides upstream from the RNA 3' end. TC formed on ssDN A (U ptain and Chamberlin 1997) or by template hopping to short DNAs that only occupy the downstream half of RN AP's DNA-binding surfaces (N udller et al. 1996) cannot recapitulate a normal TC structure in which maintenance of an unpaired transcription bubble necessarily imposes a destabilizing contribution to the overall free energy of the TC (Yager and von Hippel 1991).

If antisense oligonucleotides merely acted to prevent backtracking, it seems more likely that pairing to -12 would be sufficient to trigger transcript release at a terminator, as the pause hairpin blocks effectively backtracking even by 1 nucleotide to a conformation able to undergo pyrophosphorolysis. Likewise, if disruption of protein-RN A interactions al one were sufficient to destabilize the TC, then antisense oligonucleotide pai ring in the -11 to -8 region should exert some effect as these are the bases that appear to reside in the RN A exit channel (N udler et al . 1997) and thus to stabilize the downstream DN A clamp. On the other hand, it seems reasonable that the -8 RNA-DNA base pair could play a critical role in maintaining an unpaired transcription bubble. If the transcription bubble normally is maintained by a combination of RNAP-DNA interaction and RNA-DNA base-pairing, then exposure of the -8 template base to pairing with the nontemplate strand might reduce the transcription bubble bel ow some critical size that can be stabilized by RNAP. We favor the idea that a minimal size of the hybrid is critical, rather than only its stability, for two reasons. First, if reducing hybrid stability per se were critical for transcript release, then oligonucleotides that disrupted more of the hybrid than the -7 oligonucleotide (e.g., -5 and -3 ol igonucleotides) should have produced a higher efficiency of release, rather than the sharp boundary in destabilization that we observed (see Fig. 3). Second, substitution of iodo-UMP at three positions within the 3 '-proximal region, which is predicted to increase the stability of RNA-DNA hybrid (Ferrer et al. 1997), does not reduce the efficiency of -7 oligonucleotide-stimulated transcript rel ease (I. Artsi movitch 
and R. Landick, unpubl.). However, because transcript release at the pause requires high salt, even with the -7 antisense oligonucleotide, there must be an additional destabilizing force at a $\rho$-independent terminator. It is tempting to speculate that this is provided by the three $\mathrm{U}$ residues invariably present immediately after essentially all $\rho$-independent terminator hairpins (d'Aubenton Carafa et al. 1990). If terminator hairpin di sruption of the -8 RNA-DN A base pair can nucleate bubble collapse, three immediately adjacent, weak $\mathrm{rU} \cdot \mathrm{dA}$ base pai rs may cause it to become favorable even without the contribution of $\mathrm{Cl}^{-}$competition for RN AP-nontemplate strand interaction. Because the actual $3^{\prime}$ end of a terminated RN A can be shifted slightly downstream by accelerating nucleotide addition (M cDowell et al. 1994), the normal heterogeneity in terminated RNA 3' ends may arise because chain extension continues until bubble collapse is complete.

Further study will be required to test these ideas about transcript release, which we are led to by consideration of ability of some antisense oligonucleoti des to trigger by disrupting a critical interaction of the -8 nascent RN A base. However, our results clearly demonstrate that some type of paused TC must be formed before these events become possible.

\section{Materials and methods}

Sources of proteins, DNAs, and oligonucleotides

RNA polymerase was purified from Escherichia coli strain MRE600 (Midwest Grain Processing Co.) using the method of Burgess and Jendrisak (1975) with modifications (Hager et al. 1990). His-tagged RNA polymerase was prepared as described previously (Wang et al. 1995). Transcription templates were pre pared by PCR amplification of pCL102b (wild-type; Chan and Landick 1997) or pDW308 (MS hairpin; Wang et al. 1995) with primers 947 and 645. All DNA oligonucleotides were obtained from Operon Technologies. Oligonucl eotides -7 to -49 and the noncomplementary control ol igonucleotide were 22 nucleotide in length. Oligonucleotides -5 and -3 were 24 and 26 nucleotides, respectively, with 3 ' ends identical to the -7 oligonucleotide. Oligonucleotide UG-15 (GGGGGCTGGTCGGGGTGG; Fig. 2B) was designed to form $U-G$ base pairs with nascent RNA; it is predicted not to form a stable hybrid with the nontemplate DN A strand (8 mismatches/ 18 nucleotides). For in vitro transcription reactions all oligonucleotides were used at 500-fold molar excess relative to the ternary complex.

\section{In vitro transcription reactions}

A29 TCs were formed at $40 \mathrm{~nm}$ in transcription buffer $(20 \mathrm{~mm}$ Tris $\mathrm{HCl}, 20 \mathrm{~mm} \mathrm{NaCl}, 14 \mathrm{~mm} \mathrm{M} \mathrm{gCl} 2,14 \mathrm{~mm} \beta$-mercaptoethanol, $0.1 \mathrm{~mm} \mathrm{Na} 2$ EDTA) with ${ }^{32} \mathrm{P}$ derived from [ $\left.\alpha^{32} \mathrm{P}\right]$ CTP ( $\mathrm{N} \mathrm{ew}$ England Nuclear; $3000 \mathrm{Ci} / \mathrm{mmole}$ ) as described previously (Landick et al. 1996). Immobilized A29 TCs were formed with 3 pmoles of His-tagged RNA polymerase immobilized on $\mathrm{Ni}^{2+}$ NTA agarose beads (Qiagen), moved stepwise to the desired template positions by successive rounds of incubation with subsets of NTPs (Wang et al. 1995), and then kept on ice before use. Where indicated, preformed paused complexes were el uted from the beads with $150 \mathrm{~mm}$ imidazole and then diluted to $30 \mathrm{~mm}$ imidazole; control experiments demonstrated that this concen- tration of imidazole did not affect pausing (data not shown). When used, $\mathrm{KCl}$ and DN A or RN A oligonucleotides were added to $1 \mathrm{M}$ and at 500-fold molar excess, respectively, to the hal ted complexes, followed by $5 \mathrm{~min}$ of incubation at room temperature and equilibration at $37^{\circ} \mathrm{C}$. Elongation was allowed to resume by addition of $10 \mu \mathrm{M}$ GTP, $150 \mu \mathrm{m}$ each of ATP, CTP, UTP (Pharmacia), and $100 \mu \mathrm{g}$ heparin $/ \mathrm{ml}$. Samples were taken at the desired time points and mixed with the equal volume of $2 \times$ stop solution (Landick et al. 1996). After completion of the time course, the reactions were incubated for an additional $5 \mathrm{~min}$ with $250 \mu \mathrm{M}$ each NTP (chase).

\section{Pyrophosphorolysis and transcript release assays}

Immobilized on $\mathrm{N}^{2+}$-NTA beads complexes were walked to the desired positions on the template, preincubated for $5 \mathrm{~min}$ at room temperature in the presence of 500 -fold molar excess of oligonucleotides, $1 \mathrm{M} \mathrm{KCl}$, or both, and then equilibrated at $37^{\circ} \mathrm{C}$. Halted complexes were treated with increasing concentrations of $\mathrm{PP}_{\mathrm{i}}(1 \mu \mathrm{M}, 10 \mu \mathrm{m}, 100 \mu \mathrm{M}$, and $1 \mathrm{~mm})$ in transcription buffer for $15 \mathrm{~min}$ at $37^{\circ} \mathrm{C}$, washed with transcription buffer five times and mixed with equal volume of $2 \times$ stop solution. Alternatively, immobilized complexes were chased for $5 \mathrm{~min}$ at $37^{\circ} \mathrm{C}$ with $250 \mu \mathrm{M}$ NTPs while still on beads. The supernatants (released RN A) were mixed with equal volume of $2 \times$ stop solution; the beads (arrested or paused RNA) were washed four times with transcription buffer and resuspended in $1 \times$ stop solution. Samples were analyzed on $10 \%$ denaturing gels.

\section{Sample analysis and quantitation}

Samples were denatured for $2 \mathrm{~min}$ at $90^{\circ} \mathrm{C}$ and el ectrophoresed through 9\% denaturing gels (19:1 (wt/wt) acrylamide to bisacrylamide, $7 \mathrm{~m}$ urea) in 1XTBE [44 mM Tris-borate ( $\mathrm{pH}$ 8.3), 7.5 mM EDTA]. Relative concentrations of RNA species were determined using a Phosphorlmager and ImageQuaNT software from Molecular Dynamics. Pause half-lives (the time period during which half of the complexes enter the elongation pathway) and efficiencies (fraction of transcribing RNAP molecules that recognize the pause) were determined by nonlinear regression analysis (M icrosoft Excel) and kinetic simulation (KIN SIM and FITSIM programs) as described previously (Landick et al. 1996).

\section{Acknowledgments}

We thank members of the Landick laboratory for many productive discussions and for suggesting revisions during preparation of the manuscript. This work was supported by $\mathrm{N}$ ational Institutes of Health grant GM 38660.

The publication costs of this article were defrayed in part by payment of page charges. This article must therefore be hereby marked 'advertisement' in accordance with 18 USC section 1734 solely to indicate this fact.

\section{References}

Borukhov, S., V. Sagitov, and A. Goldfarb. 1993. Transcript cleavage factors from $\mathrm{E}$. coli. Cell 72: 459-466.

Burgess, R.R. and J.J. Jendrisak. 1975. A procedure for the rapid, large-scale purification of Escherichia coli DNA-dependent RNA polymerase involving polymin $P$ precipitation and DNA-cellulose chromatography. Biochemistry 14:46344638.

Chamberlin, M.J. 1995. N ew models for the mechanism of tran- 
scription elongation and its regulation. In The Harvey lectures, pp. 1-21. Wiley-Liss, N ew York, NY.

Chan, C. and R. Landick. 1993. Dissection of the his leader pause site by base substitution reveals a multipartite signal that includes a pause RN A hairpin. J. Mol. Biol. 233: 25-42.

- - . 1997. Effects of neutral salts of transcript el ongation and pausing suggest the his leader pause RNA hairpin interacts with an easily disordered region of RN A polymerase. J. Mol. Biol. 268: 37-53.

Chan, C., D. Wang, and R. Landick. 1997. Spacing from the transcript $3^{\prime}$ end determines whether a nascent RN A hairpin interacts with RNA polymerase to prolong pausing or triggers termination. J. Mol. Biol. 268: 54-68.

Cheng, S.-W., E.C. Lynch, K.R. Leason, D.L. Court, B.A. Shapiro, and D.I. Friedman. 1992. Functional importance of se quence in the stem-loop of a transcription terminator. Science 254: 1205-1207.

d'Aubenton Carafa, Y., E. Brody, and C. Thermes. 1990. Prediction of Rho-independent Escherichia coli transcription terminators. A statistical analysis of their RNA stem-loop structures. J. Mol. Biol. 216: 835-858.

Erie, D.A., T.D. Yager, and P.H. von Hippel. 1992. The singlenucleotide addition cycle in transcription: A biophysical and biochemical perspective. Annu. Rev. Biophys. Biomol. Struct. 21: 379-415.

Farnham, P.J. and T. Platt. 1980. A model for transcription termination suggested by studies on the trp attenuator in vitro using base analogs. Cell 20: 739-748.

Feng, G., D.N. Lee, D. Wang, C.L. Chan, and R. Landick. 1994. GreA-induced transcript cleavage in transcription complexes containing Escherichia coli RNA polymerase is controlled by multiple factors, including nascent transcript location and structure. J. Biol. Chem. 269: 22282-22294.

Ferrer, E., M. Wiersma, B. Kazimierczak, C.W. Muller, and R. Eritja. 1997. Preparation and properties of oligodeoxynucleotides containing 5-iodouracil and 5-bromo- and 5-iodocytosine. Bioconjug. Chem. 8: 757-761.

Fisher, R. and C. Yanofsky. 1983. A complementary DN A oligomer releases a transcription pause complex. J. Biol. Chem. 258: 9208-9212.

- - 1 1984. U se of complementary DN A oligomers to probe trp leader transcript secondary structures involved in transcription pausing and termination. Nucleic Acids Res. 12: 3295-3302.

Gamper, H.B. and J.E. Hearst. 1982. A topological model for transcription based on unwinding angle analysis of $E$. coli RNA polymerase binary, initiation and ternary complexes. Cell 29: 81-90.

Guajardo, R. and R. Sousa. 1997. A model for the mechanism of polymerase translocation. J. Mol. Biol. 265: 8-19.

Hager, D.A., D.J. Jin, and R.R. Burgess. 1990. Use of Mono Q high-resolution ion-exchange chromatography to obtain highly pure and active Escherichia coli RNA polymerase. Biochemistry 29: 7890-7894.

Kashlev, M., E. Nudler, K. Severinov, S. Borukhov, N. Kommisarova, and A. Goldfarb. 1996. Histidine-tagged RNA polymerase of Escherichia coli and transcription in solid phase. Methods Enzymol. 274: 326-334.

Komissarova, N. and M. Kashlev. 1997a. Arrest of transcription: E. coli RN A polymerase transl ocates backward leaving the 3' end of the RNA intact and extruded. Proc. Natl. Acad. Sci. 94: $1755-1760$.

- - - 1997b. RN A polymerase switches between inactivated and activated states by translocating back and forth along the DN A and the RN A. J. Biol. Chem. 272: 15329-15338.

Landick, R. 1997. RN A polymerase slides home: Pause and ter- mination site recognition. Cell 88: 741-744.

Landick, R., D. Wang, and C. Chan. 1996. Quantitative analysis of transcriptional pausing by RNA polymerase: The his leader pause site as a paradigm. Methods Enzymol. 274: 334352.

Lee, D.N. and R. Landick. 1992. Structure of RNA and DNA chains in paused transcription complexes containing Escherichia coli RNA polymerase. J. Mol. Biol. 228: 759-777.

Leirmo, S., C. Harrison, D.S. Cayley, R.R. Burgess, and M.T. Record Jr. 1987. Replacement of potassium chloride by potassium glutamate dramatically enhances protein-DNA interactions in vitro. Biochemistry 26: 2095-2101.

Levin, J.R. and M.J. Chamberlin. 1987. M apping and characterization of transcriptional pause sites in early genetic region of bacteriophage T7. J. Mol. Biol. 196: 61-84.

McDowell, J.C., J.W. Roberts, D.J. Jin, and C. Gross. 1994. Determination of intrinsic transcription termination efficiency by RN A polymerase elongation rate. Science 266: 822-825.

Mooney, R., I. Artsimovitch, and R. Landick. 1998. Information processing by RNA polymerase: Recognition of regulatory signals during RNA chain elongation. J. Bacteriol. 180: 3265-3275.

Nudler, E., M. Kashlev, V. Nikiforov, and A. Goldfarb. 1995. Coupling between transcription termination and RN A polymerase inchworming. Cell 81: 351-357.

Nudler, E., E. A vetissova, V. Markovstov, and A. Goldfarb. 1996. Transcription processivity: RN A polymerase-DN A interactions hol ding together the el ongation complex. Science 273: 211-217.

Nudler, E., A. Mustaev, E. Lukhtanov, and A. Goldfarb. 1997. The RNA:DNA hybrid maintains the register of transcription by preventing backtracking of RNA polymerase. Cell 89: 33-41.

Pal angat, M., T. Meier, R. Keene, and R. Landick. 1998. Transcriptional pausing at +62 of the HIV-1 nascent RN A modulates formation of the TAR RNA structure. Mol. Cell 1: 1033-1042.

Reeder, T. and D. Hawley. 1996. Promoter proximal sequences modulate RNA polymerase II el ongation by a novel mechanism. Cell 87: 767-777.

Reisbig, R.R. and J.E. Hearst. 1981. Escherichia coli deoxyribonucleic acid dependent ribonucleic acid polymerase transcriptional pause sites on SV40 DNA F1. Biochemistry 20: 1907-1918.

Reynolds, R. and M.J. Chamberlin. 1992. Parameters affecting transcription termination by Escherichia coli RN A polymerase. II. Construction and analysis of hybrid terminators. J. Mol. Biol. 224: 53-63.

Reynolds, R., R.M. Bermúdez-Cruz, and M.J. Chamberlin. 1992. Parameters affecting transcription termination by Escherichia coli RN A polymerase. Analysis of 13 rho-independent terminators. J. Mol. Biol. 224: 31-51.

Richardson, J. and J. Greenblatt. 1996. Control of RNA chain elongation and termination. In Escherichia coli and Salmonella : Cellular and molecular biology (ed. F. N eidhardt, R. Curtiss III, J. Ingraham, E. Lin, K. Low, B. Magasanik, W. Reznikoff, M. Riley, M. Schaechter, and H. Umbarger), pp. 822-848. ASM Press, Washington, D.C.

SantaLuca, J. Jr., R. Kierzek, and D. Turner. 1992. Context dependence of hydrogen bond free energgy reveal ed by substitutions in an RN A hairpin. Science 256: 217-219.

Telesnitsky, A. and M. Chamberlin. 1989. Terminator-distal sequences determine the in vitro efficiency of the early terminators of bacteriophages T3 and T7. Biochemistry 28: $5210-5218$.

Uptain, S. and M. Chamberlin. 1997. Escherichia coli RNA 


\section{Artsimovitch and Landick}

polymerase terminates transcription efficiently at rho-independent terminators on single-stranded DNA templates. Proc. Natl. Acad. Sci. 94: 13548-13553.

Uptain, S., C. Kane, and M. Chamberlin. 1997. Basic mechanisms of transcript el ongation and its regulation. Annu. Rev. Biochem. 66: 117-172.

von Hippel, P.H. and T.D. Yager. 1991. Transcript elongation and termination are competitive kinetic processes. Proc. Natl. Acad. Sci. 88: 2307-2311.

Wang, D. and R. Landick. 1997. Preferential interaction of the his pause RN A hairpin with RN A polymerase $\beta$ subunit residues 904-950 correlates with strong transcriptional pausing. Proc. Natl. Acad. Sci. 94: 8433-8438.

Wang, D., T. Meier, C. Chan, G. Feng, D. Lee, and R. Landick. 1995. Discontinuous movements of DN A and RNA in E. coli RNA polymerase accompany formation of a paused transcription complex. Cell 81: 341-350.

Wilson, K. and P. von Hippel. 1995. Transcription termination at intrinsic terminators: The role of the RN A hairpin. Proc. Natl. Acad. Sci. 92: 8793-8797.

Winkler, M., K. Mullis, J. Barnett, I. Stroynowski, and C. Yanofsky. 1982. Transcription termination at the tryptophan operon attenuator is decreased in vitro by an oligomer complementary to a segment of the leader transcript. Proc. Natl. Acad. Sci. 79: 2181-2185.

Yager, T.D. and P.H. von Hippel. 1991. A thermodynamic analysis of RNA transcript elongation and termination in Escherichia coli. Biochemistry 30: 1097-1118.

Zaychikov, E., L. Denissova, and H. Heumann. 1995. Translocation of the Escherichia coli transcription complex observed in the registers 11 to 20: 'jumping' of RNA polymerase and asymmetric expansion and contraction of the transcription bubble. Proc. Natl. Acad. Sci. 92: 1739-1743. 


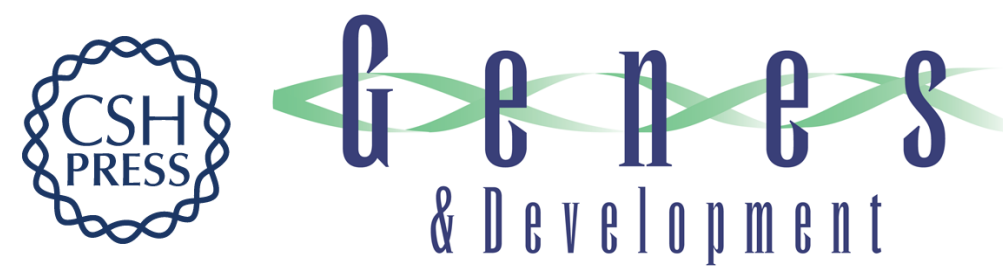

\section{Interaction of a nascent RNA structure with RNA polymerase is required for hairpin-dependent transcriptional pausing but not for transcript release}

Irina Artsimovitch and Robert Landick

Genes Dev. 1998, 12:

Access the most recent version at doi:10.1101/gad.12.19.3110

$\begin{array}{ll}\text { References } & \begin{array}{l}\text { This article cites } 44 \text { articles, } 14 \text { of which can be accessed free at: } \\ \text { http://genesdev.cshlp.org/content/12/19/3110.full.html\#ref-list-1 }\end{array}\end{array}$

License

Email Alerting Receive free email alerts when new articles cite this article - sign up in the box at the top Service right corner of the article or click here.

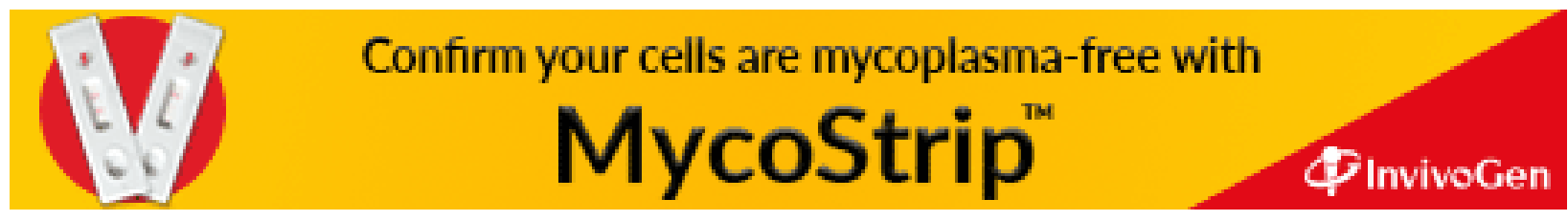

